\title{
Visible Light-Driven Gas-Phase Artificial Photosynthesis Reactions over Ruthenium Metal Nanoparticles Modified with Anatase $\mathrm{TiO}_{2}$
}

\author{
Eduardo Morais $\mathbb{D}^{1},{ }^{1}$ Colin O'Modhrain, ${ }^{1}$ K. Ravindranathan Thampi $\mathbb{D}^{2}{ }^{2}$ \\ and James A. Sullivan $\mathbb{D}^{1}$ \\ ${ }^{1}$ UCD School of Chemistry, University College Dublin, Belfield, Dublin 4, Ireland \\ ${ }^{2} U C D$ School of Chemical and Bioprocess Engineering, University College Dublin, Belfield Dublin 4, Ireland \\ Correspondence should be addressed to K. Ravindranathan Thampi; ravindranathan.thampi@ucd.ie \\ and James A. Sullivan; james.sullivan@ucd.ie
}

Received 31 January 2019; Accepted 5 March 2019; Published 30 April 2019

Guest Editor: Wei Wei

Copyright (@) 2019 Eduardo Morais et al. This is an open access article distributed under the Creative Commons Attribution License, which permits unrestricted use, distribution, and reproduction in any medium, provided the original work is properly cited.

\begin{abstract}
Ruthenium metal nanoparticles with a narrow size distribution have been synthesised via a solvothermal method. The solids were characterised using a range of analytical techniques (XRD, TEM, TPD, and XPS) and tested in the $\mathrm{CO}_{2}+\mathrm{H}_{2} \mathrm{O}$ reaction under simulated solar radiation, showing photocatalytic activity towards the production of $\mathrm{CH}_{4}$ and $\mathrm{CO}$. The photocatalysis was promoted through a plasmonic excitation of the $\mathrm{Ru}$. The addition of $\mathrm{Ti}$ to the preparation resulted in the formation of anatase $\mathrm{TiO}_{2}$. Notwithstanding the fact that the energy of the light used during the photocatalysis was insufficient to excite $\mathrm{TiO}_{2}$, its presence affects the catalysts' optical and chemical properties and the product $\left(\mathrm{CH}_{4} / \mathrm{CO}\right)$ ratios, favouring the evolution of $\mathrm{CO}$ over that of $\mathrm{CH}_{4}$ (suggesting exciton transfer to $\mathrm{TiO}_{2}$ from plasmonically excited $\mathrm{Ru}$ ).
\end{abstract}

\section{Introduction}

Increasing concentrations of atmospheric $\mathrm{CO}_{2}$ have drawn considerable attention in the scientific sphere driving researchers to seek strategies to reduce current levels and curtail overall emissions $[1,2] . \mathrm{CO}_{2}$ utilisation is a desirable strategy as it can potentially lead to decreased levels of atmospheric $\mathrm{CO}_{2}$ and the generation of products that aid energy and raw material demand. Thus, with an appropriate process, from an undesired waste, $\mathrm{CO}_{2}$ becomes a valuable and cheap feedstock $[3,4]$.

Reduction of $\mathrm{CO}_{2}$ using $\mathrm{H}_{2} \mathrm{O}$ involves the breaking of strong $\mathrm{C}=\mathrm{O}$ and $\mathrm{O}-\mathrm{H}$ bonds and thus requires energy input $[5,6]$. The photoconversion of $\mathrm{CO}_{2}$ is performed by nature through photosynthesis [7]. Artificial photosynthesis (AP) involves the reduction of $\mathrm{CO}_{2}$ using $\mathrm{H}_{2} \mathrm{O}$ and solar energy in a nonbiological system. However, $\mathrm{C}=\mathrm{O}$ and $\mathrm{O}-\mathrm{H}$ bonds are optically inert in the range of nearUV and visible light $(200-900 \mathrm{~nm})$ making the use of a photocatalyst a requirement $[1,7,8]$. The photochemical reduction of $\mathrm{CO}_{2}$ is a multiple electron transfer process leading to the formation of many different products ranging between $\mathrm{CO}$ and $\mathrm{CH}_{4}$ and including all semireduced $\mathrm{C} 1$ and $\mathrm{C} 2$ species $[8,9]$. Following over 40 years of research on this reaction, the scientific community is still a long way from producing efficient and viable devices for promoting artificial photosynthesis and there are many unresolved questions surrounding the reaction mechanisms and other parametric effects $[9,10]$.

Nanocrystals of noble metals have been used in various applications including electronics, optics, magnetics, and catalysis and exhibit unique electronic, photonic, and catalytic properties compared to their bulk counterparts [11]. Ruthenium $(\mathrm{Ru})$ is a widely used catalyst for the promotion of active and selective $\mathrm{CO}_{2}$ and organic reactions [12, 13]. Despite being an important element in catalysis, the application of Ru nanoparticles in the AP reaction, to our knowledge, has not been reported. This study describes a facile 
solvatothermal approach to fabricate nanoparticles of ruthenium (in the presence and absence of $\mathrm{TiO}_{2}$ ) from an ethanol solvent.

Three catalysts were prepared. The materials were characterised, and their catalytic activity was investigated in the AP reaction under batch reaction conditions. The described results show the first example of the use of metallic nanoparticles in an artificial photosynthetic reaction without the aid of a semiconductor component. It is also the first example of plasmon-promoted photocatalysis over $\mathrm{Ru}$ nanoparticles and of plasmon excitation transfer from $\mathrm{Ru}$ to $\mathrm{TiO}_{2}$.

\section{Experiment}

2.1. Preparation of the Photocatalysts. The ruthenium-based photocatalysts were prepared using a solvothermal route. At room temperature, $\mathrm{RuCl}_{3} \cdot 3 \mathrm{H}_{2} \mathrm{O}$ (Sigma-Aldrich, $100 \mathrm{mg}$, $0.5 \mathrm{mmol}$ ) was left to equilibrate overnight in absolute ethanol (Fischer, $12 \mathrm{~mL}$ ). The resulting solution was then transferred to a $20 \mathrm{~mL}$ Teflon-lined, stainless-steel autoclave (Parr) and heated at $160^{\circ} \mathrm{C}$ for 12 hours. The resulting solid was centrifuged, washed with distilled water and acetone several times, and dried at $60^{\circ} \mathrm{C}$ overnight. This procedure was repeated adding $\mathrm{TiCl}_{3}$ (Acros, 20\% in ethanol) to the $\mathrm{RuCl}_{3}$ solution after the equilibration. The addition of $\mathrm{TiCl}_{3}$ was carried out dropwise at two $\mathrm{Ru}$ : Ti molar ratios: 10:1 and $1: 10$. Thus, three different $\mathrm{Ru}_{x} \mathrm{Ti}_{y}$ samples were prepared $\left(\mathrm{Ru}_{1} \mathrm{Ti}_{0}, \mathrm{Ru}_{10} \mathrm{Ti}_{1}\right.$, and $\left.\mathrm{Ru}_{1} \mathrm{Ti}_{10}\right)$, where $x$ and $y$ are the respective $\mathrm{Ru}$ : Ti molar ratios. These are designated as $100 \% \mathrm{Ru}$, $10 \% \mathrm{TiO}_{2} / \mathrm{Ru}$, and $10 \% \mathrm{Ru} / \mathrm{TiO}_{2}$ in the text.

2.2. Characterisation Methods. X-ray powder diffraction analysis was carried out on a Siemens D500 Kristalloflex diffractometer using $\mathrm{Cu} \mathrm{K} \alpha$ radiation $(\lambda=1.54056 \AA)$. The voltage and the current were set to $40 \mathrm{kV}$ and $30 \mathrm{~mA}$, respectively, and the scan was conducted in $2 \theta$ mode, an angular range of $10-90^{\circ}, 0.01$ step per degree, and 5 seconds per step.

UV-visible spectra were recorded on a Jasco V-650 instrument equipped with an integrating sphere (ISV-722). Absorbance was recorded in the range of 190-900 nm in baseline correction mode, with background spectra being collected prior to the experiments.

A Quantachrome NovaWin2 instrument was used to obtain $\mathrm{N}_{2}$ adsorption/desorption isotherms at $77.3 \mathrm{~K}$. The BET-specific surface area $\left(S_{\mathrm{BET}}\right)$ was calculated from the linear fit of the data in the $\mathrm{N}_{2}$ adsorption/desorption isotherms over the relative pressure range $\left(P / P_{0}\right)$ of $0.05-0.30$ using the Brunauer-Emmett-Teller (BET) equation.

Samples for TEM (Transmission Electron Microscopy) analysis were dispersed in isopropanol and sonicated for 15 minutes. $10 \mu \mathrm{L}$ of the suspension was then dropped onto holey carbon films supported by copper TEM meshes. The solvent was evaporated prior to analysis. Images were recorded on a FEI Tecnai G220 TWIN microscope operated at $200 \mathrm{kV}$.

XPS (X-ray Photoelectron Spectroscopy) analysis was performed on a Kratos Axis Ultra DLD instrument. Samples

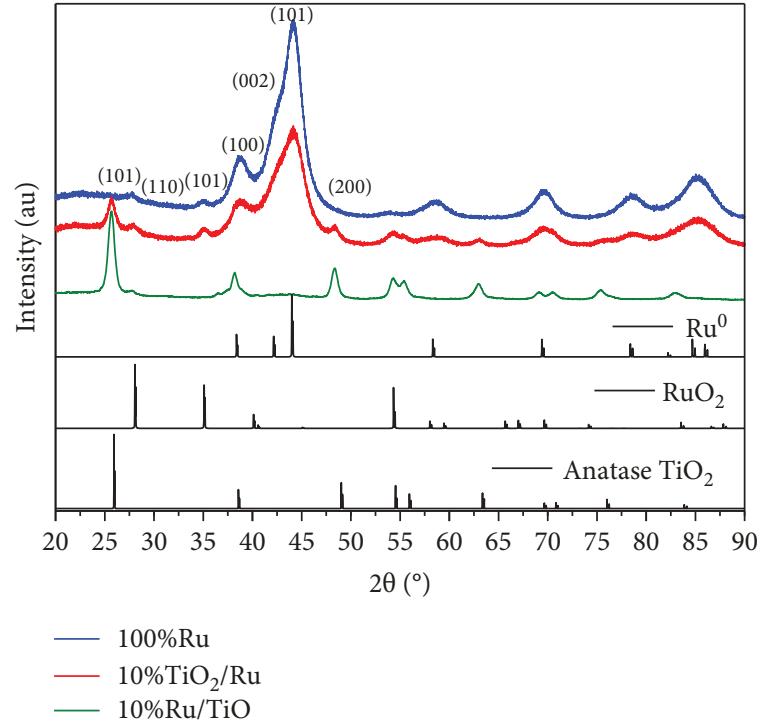

FIGURE 1: pXRD patterns of the RuTi series compared with the standards $\mathrm{Ru}^{0}, \mathrm{RuO}_{2}$, and $\mathrm{TiO}_{2}$.

TABLE 1: BET surface areas and weight percentages (as derived from pXRD) of the phases in the RuTi series.

\begin{tabular}{lcccc}
\hline Samples & $\mathrm{SSA}\left(\mathrm{m}^{2} \mathrm{~g}^{-1}\right)$ & $\mathrm{Ru}(\mathrm{wt} \%)$ & $\mathrm{RuO}_{2}(\mathrm{wt} \%)$ & $\mathrm{TiO}_{2}(\mathrm{wt} \%)$ \\
\hline $100 \% \mathrm{Ru}$ & 195 & 96 & 4 & 0 \\
$10 \% \mathrm{TiO}$ & 2 \\
$10 \% \mathrm{Ru}$ & 177 & 86 & 6 & 8 \\
$10 \% \mathrm{RiO}$ & 68 & 6 & 4 & 90 \\
\hline
\end{tabular}

for XPS were pressed into pellets using a hydraulic press prior to analysis.

TPD (Temperature Programmed Desorption) experiments were carried out using both $\mathrm{H}_{2} \mathrm{O}$ and $\mathrm{CO}_{2}$ as probe molecules. For $\mathrm{CO}_{2}$ TPD, samples were loaded into a quartz tubular reactor and held in place using quartz wool plugs. While the solid was kept under a flow of Ar $\left(100 \mathrm{~mL} \mathrm{~min}^{-1}\right)$, the reactor was housed in a furnace and heated at $110^{\circ} \mathrm{C}$ for 30 minutes to remove any physisorbed species from the surface. This system was then allowed to cool at $50^{\circ} \mathrm{C}$, and the catalyst was dosed with $5 \% \mathrm{CO}_{2}$ in a flow of $\mathrm{Ar}$ $\left(95 \mathrm{~mL} \mathrm{~min}^{-1}\right)$ until saturation was reached $(\sim 1 \mathrm{~h})$. The $\mathrm{CO}_{2}$ signal at this stage was recorded as a calibration factor, before $\mathrm{CO}_{2}$ was removed from the stream and replaced by an equivalent flow of Ar, retaining the overall flow $\left(100 \mathrm{~mL} \mathrm{~min}^{-1}\right)$. The temperature was lowered to $20^{\circ} \mathrm{C}$, and the $\mathrm{CO}_{2}$ signal (as measured using an online mass spectrometer-Prolab) returned to background levels. The catalyst was then heated from $20^{\circ} \mathrm{C}$ to $700^{\circ} \mathrm{C}$ at a ramp rate of $10^{\circ} \mathrm{C} \mathrm{min}{ }^{-1}$ while a portion of the exhaust gas was continuously monitored on the Prolab instrument. For $\mathrm{H}_{2} \mathrm{O}$ TPD experiments, a mixture $\mathrm{H}_{2} \mathrm{O} / \mathrm{Ar}$ was produced by flowing $\mathrm{Ar}\left(50 \mathrm{~mL} \mathrm{~min}^{-1}\right)$ through a bubbler containing $500 \mathrm{~mL}$ of $\mathrm{H}_{2} \mathrm{O}$ immersed in a water bath kept at $60^{\circ} \mathrm{C}$. Considering the bubbler as an isolated system and the relative vapour pressure of $\mathrm{H}_{2} \mathrm{O}$ at $60^{\circ} \mathrm{C}$ 


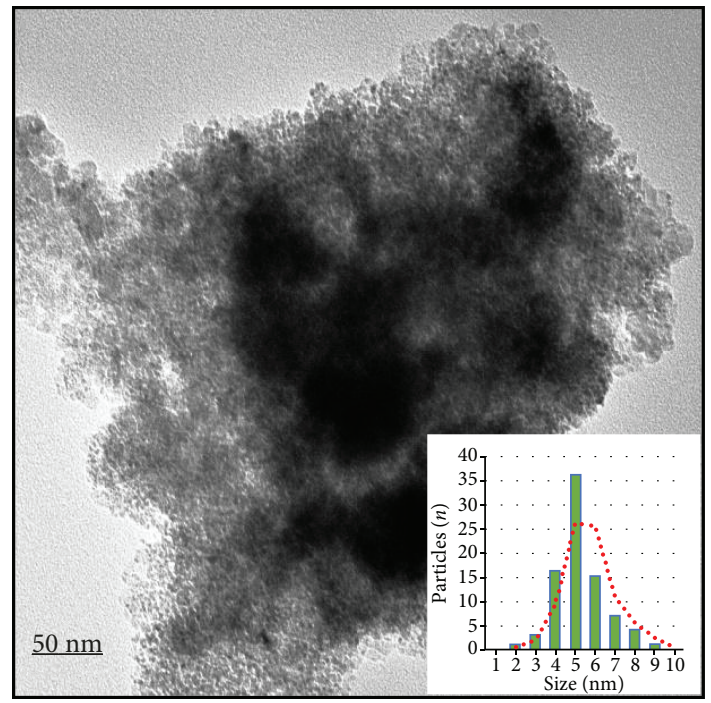

(a)

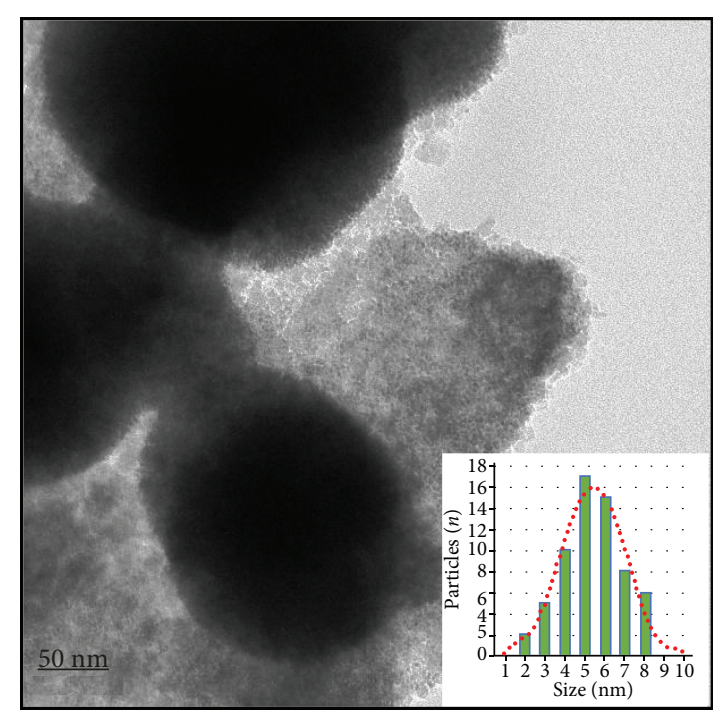

(b)

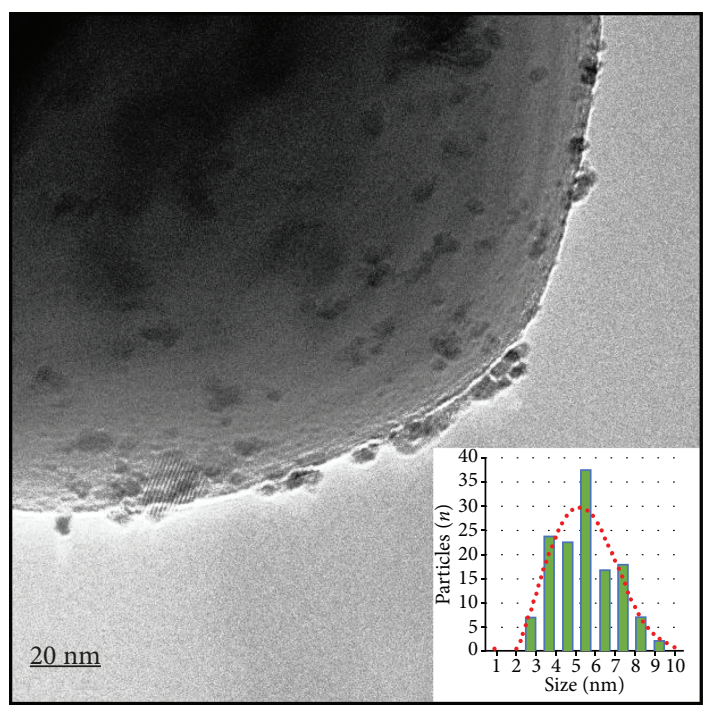

(c)

Figure 2: $(\mathrm{a}, \mathrm{b}, \mathrm{c}) \mathrm{TEM}$ images of $100 \% \mathrm{Ru}, 10 \% \mathrm{TiO}_{2} / \mathrm{Ru}$, and $10 \% \mathrm{Ru} / \mathrm{TiO}_{2}$, respectively. Insets show Ru particle size histograms.

$\left(P_{\mathrm{r}(60 \circ \mathrm{C})}\right)$ as $0.1961 \mathrm{~atm}$ [5], the resulting mixture was $7.2 \%$ $\mathrm{H}_{2} \mathrm{O}(v / v)$. This was used to dose the catalyst at $50^{\circ} \mathrm{C}$ with $3.9 \% \mathrm{H}_{2} \mathrm{O}$ in a flow of $\mathrm{Ar}\left(96.1 \mathrm{~mL} \mathrm{~min}^{-1}\right)$ until saturation was reached $(\sim 1 \mathrm{~h})$. The $\mathrm{H}_{2} \mathrm{O}$ signal at this stage was recorded as a calibration factor, before $\mathrm{H}_{2} \mathrm{O}$ was removed from the stream and replaced by an equivalent flow of $\mathrm{Ar}$, retaining the overall flow $\left(100 \mathrm{~mL} \mathrm{~min}^{-1}\right)$. The temperature was lowered to $20^{\circ} \mathrm{C}$, and the $\mathrm{H}_{2} \mathrm{O}$ signal returned to background levels. The catalyst was then heated from $20^{\circ} \mathrm{C}$ to $700^{\circ} \mathrm{C}$ at a ramp rate of $10^{\circ} \mathrm{C} \mathrm{min}^{-1}$ while a portion of the exhaust gas was continuously monitored using an online Prolab mass spectrometer.

2.3. Catalytic Activity Measurements. The catalytic evolution of gaseous products was investigated with a top irradiation photoreactor vessel under batch conditions. In a typical experiment, the catalyst $(20 \mathrm{mg})$ was loaded into the reactor $\left(73.5 \mathrm{~cm}^{3}\right)$ and initially the system was held under a flow of $\operatorname{Ar}\left(100 \mathrm{~mL} \mathrm{~min}^{-1}\right)$ while the temperature was increased to $110^{\circ} \mathrm{C}$ for 30 minutes in order to ensure that any species attached to the surface by physisorption had been removed. The temperature was then lowered to $50^{\circ} \mathrm{C}$, and a mixture of $\mathrm{H}_{2} \mathrm{O}, \mathrm{CO}_{2}$, and $\mathrm{Ar}\left(100 \mathrm{~mL} \mathrm{~min}^{-1}\right)$ was switched into the stream. The catalyst in the reactor was held under a flow of $\mathrm{CO}_{2}$ and $\mathrm{H}_{2} \mathrm{O}$ for 1 hour with a $\mathrm{CO}_{2}: \mathrm{H}_{2} \mathrm{O}$ ratio of $1: 14$. After 1 hour, the reactor was cooled at $25^{\circ} \mathrm{C}$, sealed, and placed into the chamber of an Atlas Suntest ${ }^{\mathrm{TM}} \mathrm{CPS}+$ instrument and externally irradiated by a $300 \mathrm{~W}$ Xe lamp (Figure SI 1) that only emits visible light. During the reaction, the system was cooled to ensure that the temperature was kept constant at $25^{\circ} \mathrm{C}$. The reactor was equipped with a septum which allowed sample extraction for analysis. The extraction of gaseous aliquots for GC analysis was carried out periodically using a $500 \mu \mathrm{L}$ Swagelok ${ }^{\mathrm{TM}}$ gastight syringe. The GC was Varian 


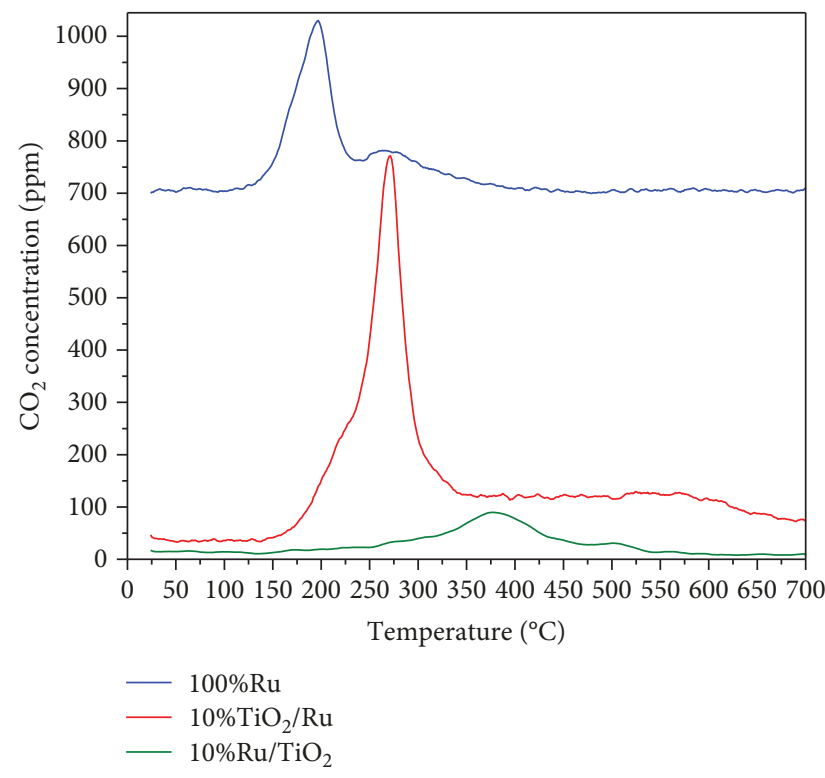

(a)

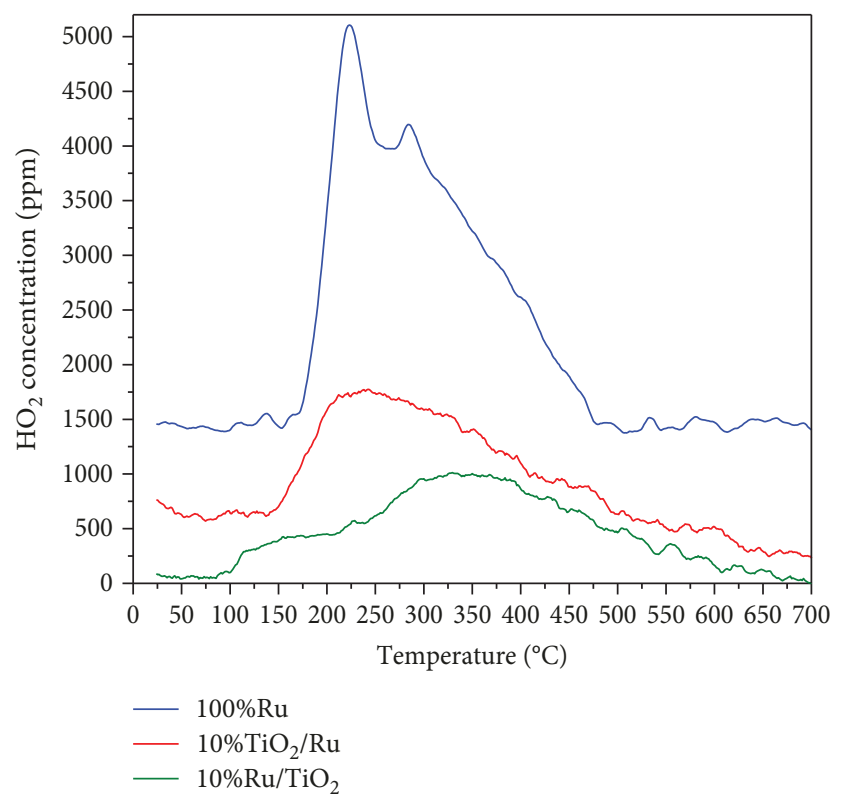

(b)

Figure 3: Displaced TPD profiles of (a) $\mathrm{CO}_{2}$ and (b) $\mathrm{H}_{2} \mathrm{O}$ from the three different materials.

GC-450 equipped with CARBOWAX and Hayesep C packed columns, a methaniser, and detectors TCD and FID. The injector, the FID, and the TCD were held at $200^{\circ} \mathrm{C}$, while the methaniser was held at $400^{\circ} \mathrm{C}$. Ar was the carrier gas with an overall flow of $50 \mathrm{~mL} \mathrm{~min}^{-1}$, and the pressure on the column was set to $30 \mathrm{psi}$. For the analysis, the initial temperature of the column was set to $50^{\circ} \mathrm{C}$, and the column was then ramped at a rate of $20^{\circ} \mathrm{C} \mathrm{min}^{-1}$ to $120^{\circ} \mathrm{C}$ and held at the final temperature for 2 minutes.

\section{Results and Discussion}

The XRD patterns of the RuTi series and reference XRD patterns are shown in Figure 1. Hexagonal ruthenium metal with a space group P63/mmc and lattice constants of $a=$ 2.704 (7) $\AA$ and $c=2.958$ (4) $\AA$ was observed in all samples via the presence of (100), (002), and (101) diffraction peaks at $2 \theta=38.7,42.2$, and $44.2^{\circ}$. A small fraction of tetragonal rutile-phase $\mathrm{RuO}_{2}(a=b=4.593$ (7) $\AA, c=2.958$ (7) $\AA$; weight percentages shown in Table 1) with a space group $\mathrm{P} 42 / \mathrm{mnm}$ was also observed in all samples, detected via the presence of (110) and (101) diffraction peaks at $2 \theta=27.8$ and $35.1^{\circ}$. With regard to Ti phases, only anatase $\mathrm{TiO}_{2}$ was detected in the $10 \% \mathrm{TiO}_{2} / \mathrm{Ru}$ and $10 \% \mathrm{Ru} / \mathrm{TiO}_{2}$ samples via the presence of (101), (103), and (200) diffraction peaks at $2 \theta=25.7,37.8$, and $48.4^{\circ}$. The anatase $\mathrm{TiO}_{2}$ was obtained in the tetragonal crystalline system with a space group I41/amd and lattice constants of $a=b=3.793$ (1) $\AA$ and $c=9.510$ (4) A. No other diffraction features associated with ruthenium- or titanium-related species were found regardless of the $\mathrm{Ru}$ : Ti molar ratio used in the preparation.

A small negative shift of $0.06^{\circ}$ and $0.10^{\circ}$ in the (110) and (101) peaks of the $\mathrm{RuO}_{2}$ phase was observed in the profiles of the $10 \% \mathrm{TiO}_{2} / \mathrm{Ru}$ and $10 \% \mathrm{Ru} / \mathrm{TiO}_{2}$ samples, respectively (when compared to the reference peaks of $\mathrm{RuO}_{2}$ ). Such a shift, which can be correlated with expansive residual strain, defects, or change in electronic configuration or atomic structure, was not detectable in the pattern of the $100 \% \mathrm{Ru}$ sample. The shift is ascribed to the inclusion of $\mathrm{Ti}$ into the $\mathrm{RuO}_{2}$ matrix in these samples. This observation obeys Vegard's law [14, 15] where the lattice of metallic substitutional solid solution is compressed with increasing solute concentration as the atomic radius of solute atoms $(\mathrm{Ti}, 176 \mathrm{pm})$ is smaller than that of the solvent atoms $(\mathrm{Ru}$, $178 \mathrm{pm})$.

TEM images of the solids are presented in Figures 2(a), 2(b) and 2(c). In all cases, the morphology of the ruthenium metal particles is spherical. This morphology can also be observed in the SEM images (Figure SI 2). The inset plot on each image displays the corresponding particle size distribution histogram of the ruthenium metal nanoparticles in the catalysts. The particle sizes ranged between 2 and $10 \mathrm{~nm}$-with an average diameter of $5 \mathrm{~nm}$ across the three samples. Neither the morphology nor the size of the $\mathrm{Ru}$ particles was affected by the introduction of anatase $\mathrm{TiO}_{2}$. This is clear in Figure 2(c) in which the ruthenium nanoparticles can be observed on the larger $\mathrm{TiO}_{2}$ particles. As for the anatase $\mathrm{TiO}_{2}$ particles in $10 \% \mathrm{Ru} / \mathrm{TiO}_{2}$, these are approximately spherical with an average size of $0.5-$ $0.7 \mu \mathrm{m}$.

It is also noteworthy that the extent of aggregation of the Ru nanoparticles differs across the three prepared samples. In the $10 \% \mathrm{TiO}_{2} / \mathrm{Ru}$, the $\mathrm{Ru}$ nanoparticles appear more aggregated than those in the $100 \% \mathrm{Ru}$ sample and in the $10 \% \mathrm{Ru} / \mathrm{TiO}_{2}$ sample, and the aggregation is found to be the least. The aggregation of Ru nanostructures into larger spherical features may decrease the surface area of the final material and affect the nature of the plasmon resonance, which is 


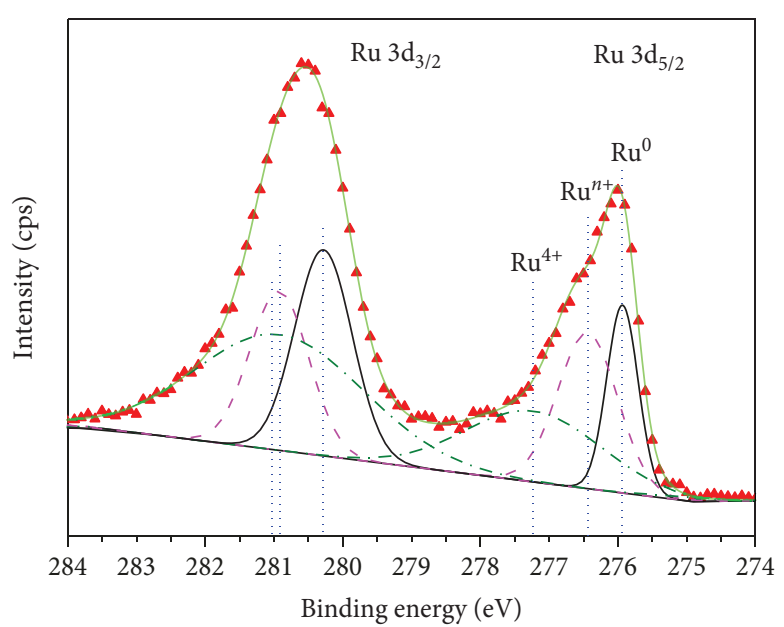

$\triangle$ Experimental data points

- Cumulative fit

(a)

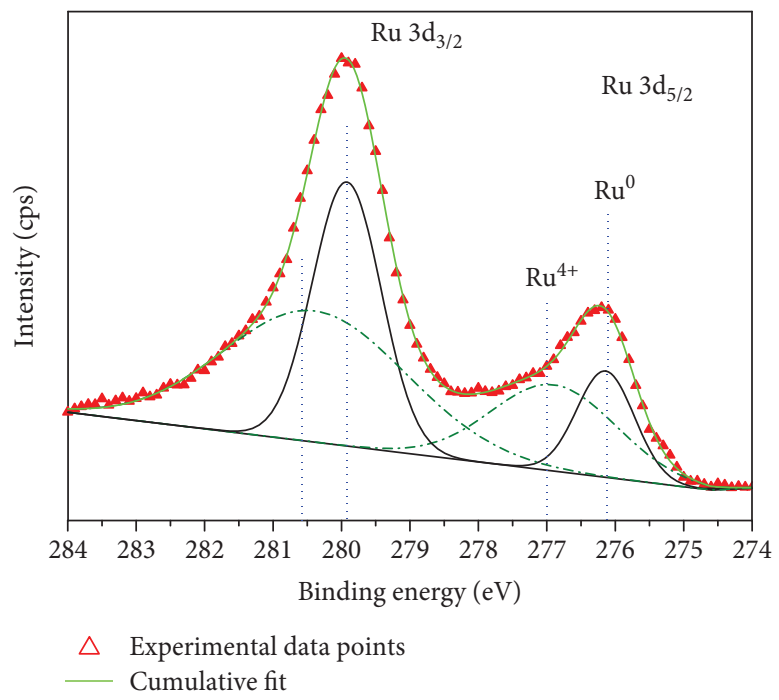

(c)

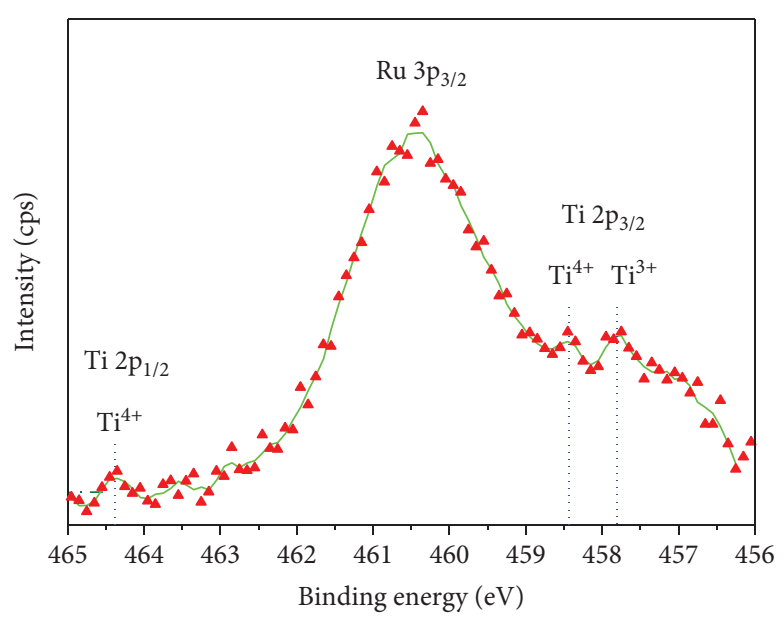

$\triangle$ Experimental data points

- Cumulative fit

(b)

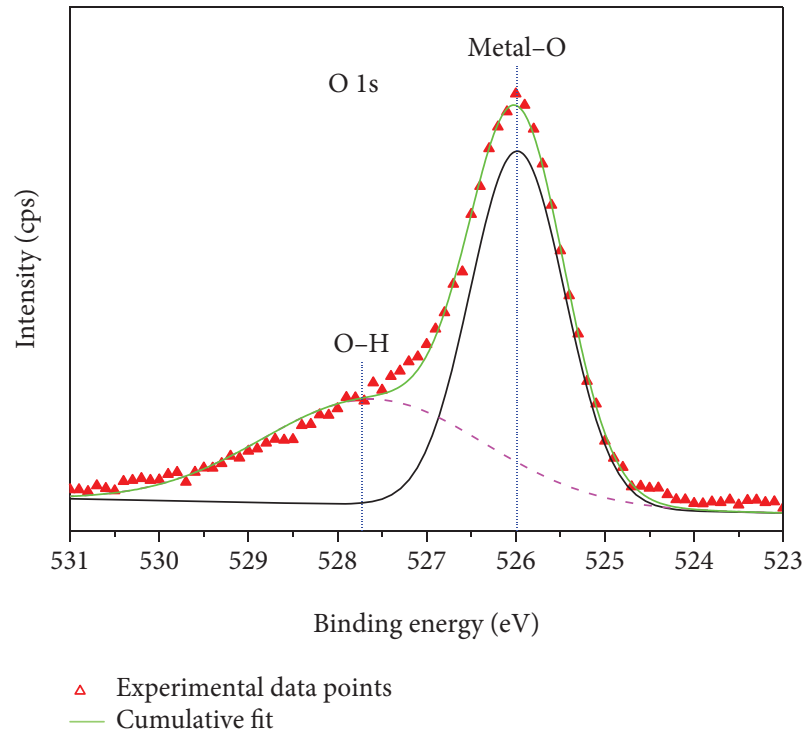

(d)

Figure 4: High-resolution XPS core-level spectra of (a) $100 \% \mathrm{Ru}(\mathrm{Ru} 3 \mathrm{~d})$, (b) $10 \% \mathrm{TiO}_{2} / \mathrm{Ru}(\mathrm{Ru} 3 \mathrm{~d}),(\mathrm{c}) 10 \% \mathrm{TiO} / 2 / \mathrm{Ru}(\mathrm{Ti} 2 \mathrm{p})$, and (d) $10 \% \mathrm{TiO}_{2} / \mathrm{Ru}(\mathrm{O} 1 \mathrm{~s})$.

known to be size dependent on these nanoparticles [16, 17]. In turn, these characteristics may impact the catalytic properties. However, the UV-visible spectra, which analyse the plasmons, do not show any conclusive difference in the plasmon band across the three samples.

3.1. Surface and Optical Properties. These materials showed appreciable BET surface areas (Table 1). The multipoint BET analysis plots are shown in Figure SI 3. The two Ruabundant samples-100\% Ru and $10 \% \mathrm{TiO}_{2} / \mathrm{Ru}$ - have much higher BET surface areas than the Ti-abundant sample$10 \% \mathrm{Ru} / \mathrm{TiO}_{2}$. This can be attributed to the different sizes of the particles (see above).

Figure 3(a) shows TPDs of $\mathrm{CO}_{2}$ from the catalyst series. The $100 \% \mathrm{Ru}$ and $10 \% \mathrm{TiO}_{2} / \mathrm{Ru}$ materials show two desorption events in each profile, confirming the presence of two $\mathrm{CO}_{2}$ accessible adsorption sites. These are well separated peaking at $T_{1}=195^{\circ} \mathrm{C}$ and $T_{2}=270^{\circ} \mathrm{C}$ in the profile from the $100 \% \mathrm{Ru}$ catalyst, while for $10 \% \mathrm{TiO}_{2} / \mathrm{Ru}$, there is a main peak at $T_{2}=270^{\circ} \mathrm{C}$ with a lower temperature shoulder at $T_{1}=220^{\circ} \mathrm{C}$. The incorporation of $10 \% \mathrm{Ti}$ strengthens the interaction between $\mathrm{CO}_{2}$ and the surface (as seen by the change in desorption temperatures) and reverses the relative concentrations of the adsorption sites. The $10 \% \mathrm{TiO}_{2} / \mathrm{Ru}$ catalyst contains the highest concentration of $\mathrm{CO}_{2}$ desorption sites with $645.6 \mu \mathrm{mol} \mathrm{g}^{-1}$ of $\mathrm{CO}_{2}$ desorbing from the saturated catalyst, compared to 439.6 and $212.5 \mu \mathrm{mol} \mathrm{g}^{-1}$ from $100 \% \mathrm{Ru}$ and $10 \% \mathrm{Ru} / \mathrm{TiO}_{2}$, respectively.

Upon increasing the Ti loading to $\sim 90 \%$, the $\mathrm{CO}_{2}$ adsorption/desorption characteristics were altered substantially. 
The extent of desorption was much lower, and it occurred at higher temperatures $\left(300-500^{\circ} \mathrm{C}\right)$, indicating the formation of stronger adsorption sites on the (mostly) $\mathrm{TiO}_{2}$ surface. These new (presumably $\mathrm{TiO}_{2}$-based) sites are more stable than those on the $100 \% \mathrm{Ru}$ and $10 \% \mathrm{TiO}_{2} / \mathrm{Ru}$ materials; however, they are less stable than the typical $\mathrm{CO}_{2}$ adsorption sites on anatase $\mathrm{TiO}_{2}$ [18]. Mao et al. have studied $\mathrm{CO}_{2}$ desorption from various anatase $\mathrm{TiO}_{2}$ samples and reported that the main desorption events occur in the $500-600^{\circ} \mathrm{C}$ range. This shift in the $\mathrm{CO}_{2}$ peaks to lower temperatures suggests that the presence of $\mathrm{Ru}$ has weakened the $\mathrm{CO}_{2}-\mathrm{TiO}_{2}$ interactions. These catalysts are also capable of adsorbing and desorbing $\mathrm{H}_{2} \mathrm{O}$ (see the $\mathrm{H}_{2} \mathrm{O}$-TPD profiles in Figure 3(b)). These profiles show that the presence of $\mathrm{TiO}_{2}$ decreases the $\mathrm{H}_{2} \mathrm{O}$ adsorption/desorption capacities of the materials. The $\mathrm{Ru}$ sample without $\mathrm{TiO}_{2}$ shows a large peak at $225^{\circ} \mathrm{C}$ with a secondary peak at $300^{\circ} \mathrm{C}$, while when $\mathrm{TiO}_{2}$ is added to the material the water desorption is singly (relatively broad feature) peaking at $250^{\circ} \mathrm{C}$ from the $10 \% \mathrm{TiO}_{2} / \mathrm{Ru}$ sample and at $\sim 350^{\circ} \mathrm{C}$ from the $10 \% \mathrm{Ru} / \mathrm{TiO}_{2}$ material. These results confirm that the samples can adsorb (and desorb) both reactants required for the AP reaction.

XPS measurements shed light on the nature of the surface of these catalysts. Figure 4(a) shows the $\mathrm{Ru} 3 \mathrm{~d}$ spectrum of the $100 \% \mathrm{Ru}$ sample. The two peaks observed in the $\mathrm{Ru} 3 \mathrm{~d}$ region are related to electron emission from $\mathrm{Ru} 3 \mathrm{~d}_{3 / 2}$ and $\mathrm{Ru} 3 \mathrm{~d}_{5 / 2}$ levels (with binding energies at 280.7 and $276.2 \mathrm{eV}$, respectively). These peaks correspond mainly to emission from hexagonal $\mathrm{Ru}^{0}$ with a coordination number of 12 and a spin-orbit splitting $\Delta$ of $4.5 \mathrm{eV}$ [19]. Upon deconvolution of this spectrum, emission from small amounts of $\mathrm{Ru}^{4+}$ (at higher energies relative to those from $\mathrm{Ru}^{0}$ ) was also detected, confirming the presence of $\mathrm{RuO}_{2}$.

The $\mathrm{Ru} 3 \mathrm{~d}$ spectrum of the $10 \% \mathrm{TiO}_{2} / \mathrm{Ru}$ material shows signals related to $\mathrm{Ru}^{0}$ and $\mathrm{Ru}^{4+}$ (as above) but also signals related to emission from $\mathrm{Ru}^{n+}$ (Figure 4(b) and Figure SI 4). The existence of $\mathrm{Ru}^{n+}(0<n<4)$ species in this catalyst must be ascribed to the added $\mathrm{Ti}$ and its effect on the electronic structure of $\mathrm{Ru}$. Kim and Winograd considered that the substitution of metal ions into the $\mathrm{RuO}_{2}$ lattice is most likely responsible for the formation of $\mathrm{Ru}^{n+}(0<n<4)$ ions via electron transfer from $\mathrm{Ti}$ to $\mathrm{Ru}^{4+}$ ions [20].

Such observations are in good agreement with the XRD results which show dissolution of $\mathrm{Ti}$ into the $\mathrm{RuO}_{2}$ lattice. Furthermore, Rodriguez et al. reported the creation of interstitial $\mathrm{M}^{n+}$ species in solid solutions of $(\mathrm{Ti}-\mathrm{Ru}) \mathrm{O}_{2}$, such as $\mathrm{Ru}^{3+}$, which may lead to undercoordinated oxygen species (oxygen vacancies) preserving the electrostatic balance [21].

The $\mathrm{Ti} 2 \mathrm{p}$ spectrum of the $10 \% \mathrm{TiO}_{2} / \mathrm{Ru}$ catalyst was also recorded (Figure $4(\mathrm{c})$ ). Emission from the Ti $2 \mathrm{p}_{1 / 2}$ and $2 \mathrm{p}_{3 / 2}$ levels with binding energies at 458.5 and $464.4 \mathrm{eV}$ is related to emission from octahedrally coordinated $\mathrm{Ti}^{4+}$. However, a second, less intense peak at lower energy, related to $\mathrm{Ti}^{3+}$, was also detected in the $\mathrm{Ti} 2 \mathrm{p}$ region. This peak must be related to incorporation of $\mathrm{Ti}$ into the $\mathrm{RuO}_{2}$ lattice. The $\mathrm{O}$ 1 s spectrum of this catalyst shows the presence of both lattice and surface hydroxyl $\mathrm{O}$ atoms.

Figure 5 shows the UV-Vis spectra of the catalysts. The absorption feature in the range of $250-358 \mathrm{~nm}$ observed in

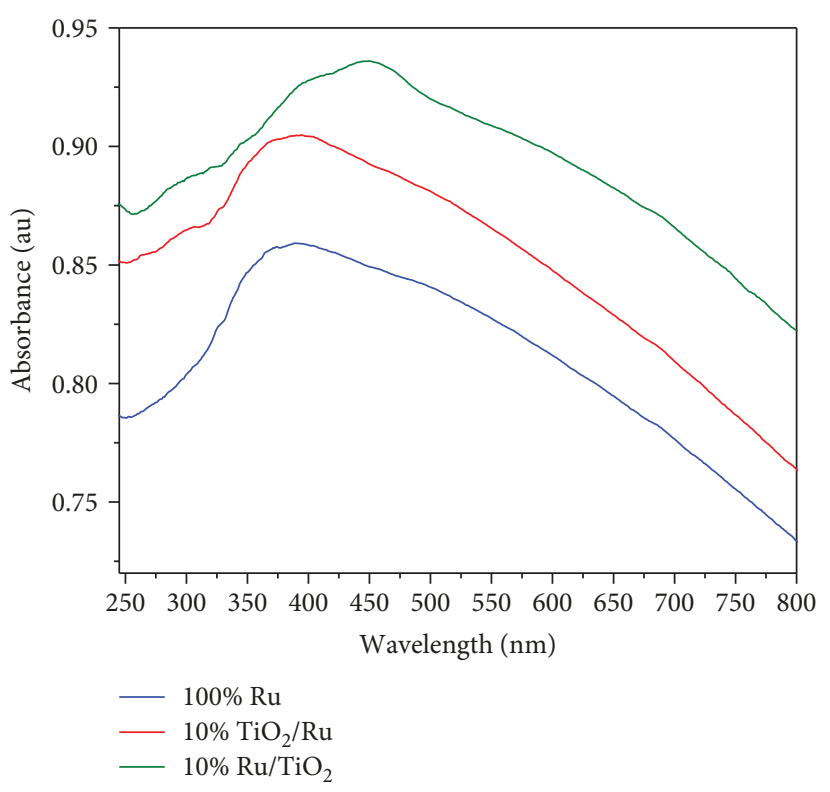

Figure 5: UV-Vis spectra of the catalysts.

the Ti-containing samples is associated with the $\mathrm{O} 2 \mathrm{p}-\mathrm{Ti}$ $3 \mathrm{~d}$ (band gap) transition of $\mathrm{TiO}_{2}$. The absorption beyond $358 \mathrm{~nm}$ towards the visible and near-infrared range $(\lambda=400-800 \mathrm{~nm})$ is significantly pronounced in the spectra of all catalysts. This has previously been attributed to interband transitions and localised surface plasmonic resonance (LSPR), i.e., surface electron oscillation under continuous electromagnetic stimuli [22-24] on $\mathrm{Ru}$ particles.

3.2. Photocatalytic Activity. The photocatalysis results are shown in Figure 6. Regarding photoreactivity, it should be noted that no products resulted from reactions that were carried out (a) in the dark or (b) in the absence of catalyst. Neither was there any detection of products when $\mathrm{P} 25 \mathrm{TiO}_{2}$ was used as a photocatalyst in the presence or absence of light.

Consumption of $\mathrm{CO}_{2}$ and production of either gaseous $\mathrm{CO}$ or $\mathrm{CH}_{4}$ were only observed when both $\mathrm{Ru}$-containing catalysts and light were present. The reaction was carried out in the presence of $\mathrm{CO}_{2}$ and $\mathrm{H}_{2} \mathrm{O}$ (with no hole scavenger agents), and evolution of $\mathrm{O}_{2}$ at a larger rate in comparison to evolution of the carbon-containing products was observed in all cases (see Figure 6(a)). The levels of $\mathrm{CH}_{4}$ and $\mathrm{CO}$ produced as a function of reaction time for the different catalysts are shown in Figure 6(b). While $\mathrm{CH}_{4}$ was the sole product observed when using the $100 \% \mathrm{Ru}$ catalyst, CO was formed alongside $\mathrm{CH}_{4}$ over the Ti-containing catalysts. In the case of the $10 \% \mathrm{TiO}_{2} / \mathrm{Ru}$ catalyst, $\mathrm{CO}$ only arose as a minor byproduct; however, over the $10 \% \mathrm{Ru} / \mathrm{TiO}_{2}$ catalyst, $\mathrm{CO}$ was produced in comparable amounts to $\mathrm{CH}_{4}$. Thus, as the quantities of $\mathrm{CO}$ involved increase with the concentration of $\mathrm{TiO}_{2}$ in the catalyst, the generation of $\mathrm{CO}$ appears to be related to the levels of $\mathrm{TiO}_{2}$ (anatase) in the material.

No carbon balance was achieved in these reactions. Attainment of one is difficult for several reasons. Firstly, at the beginning of the reaction, the reactor contains both 


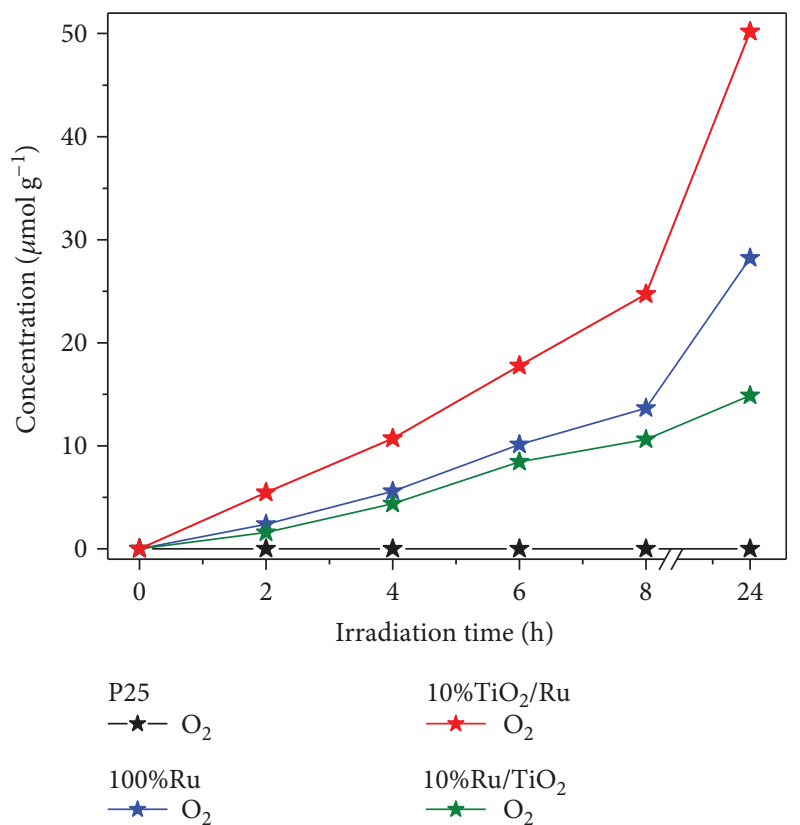

(a)

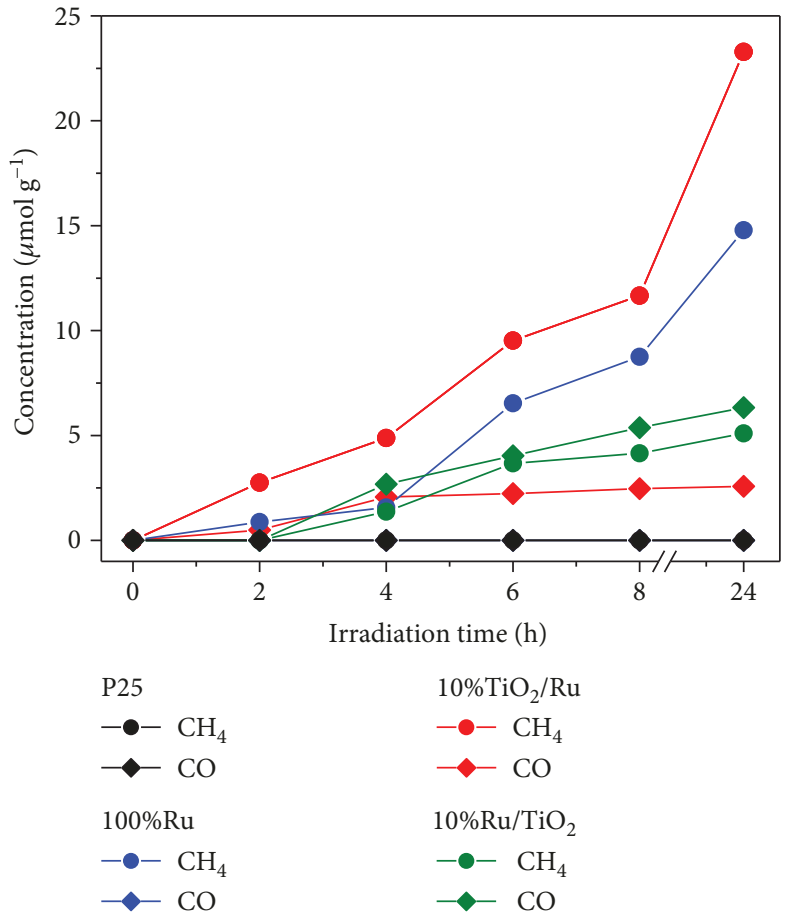

(b)

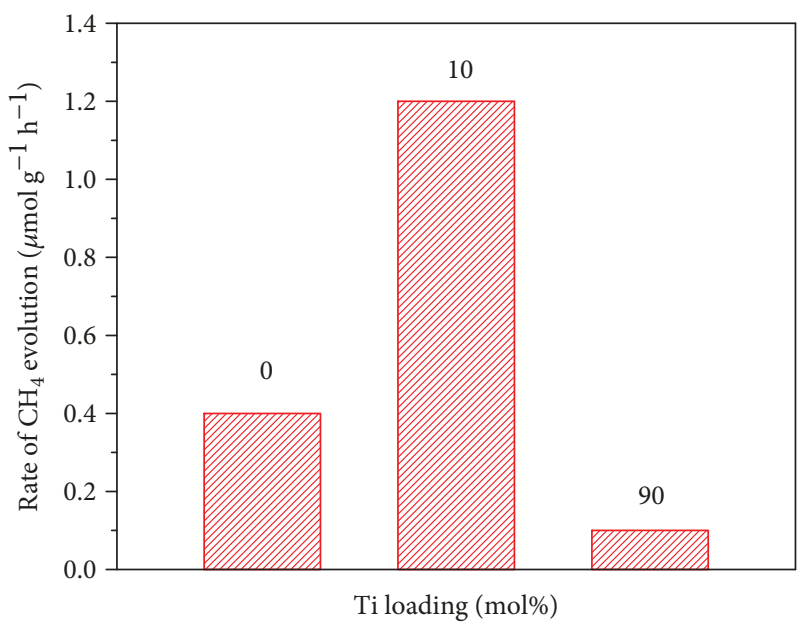

(c)

Figure 6: Evolution of (a) $\mathrm{O}_{2}$ and (b) $\mathrm{CH}_{4}$ and $\mathrm{CO}$ with time over $\mathrm{P} 25$ and the three $\mathrm{Ru}$-containing catalysts and (c) rate of $\mathrm{CO}_{2}$ conversion over each of the Ru-containing catalysts.

gaseous and adsorbed $\mathrm{CO}_{2}$. It is possible to measure the former and estimate the latter from $\mathrm{CO}_{2}$-TPD once an equilibrium is attained without any reactions involved. However, this is not the case here. This adsorbed $\mathrm{CO}_{2}$ desorbs during the course of the reaction depending upon the partial pressure of gaseous $\mathrm{CO}_{2}$ remaining to be reacted, and the attainment of this adsorption-desorption equilibration is not instantaneous.

Following the experiments, we measured the gas phase concentrations of reactants and products. This data is presented in Table 2 from the reaction over the $10 \% \mathrm{TiO}_{2} / \mathrm{Ru}$ catalyst and shows a discrepancy of $\sim 10 \%$ in the $\mathrm{C}$ balance. This is not large when considering the dynamics of the reaction
TABLE 2: Carbon balance from the artificial photosynthesis reaction carried out over the $10 \% \mathrm{TiO}_{2} / \mathrm{Ru}$ catalyst.

\begin{tabular}{lcc}
\hline & $\begin{array}{c}\text { Before reaction } \\
\left(\mathrm{mmol} \mathrm{g}^{-1}\right)\end{array}$ & $\begin{array}{c}\text { Following reaction } \\
\left(\mathrm{mmol} \mathrm{g}^{-1}\right)\end{array}$ \\
\hline In the reactor & 3.54 & 3.78 \\
Adsorbed & 0.65 & $?$ \\
Products & 0 & 0.03 \\
Total & 4.19 & 3.81 \\
\hline
\end{tabular}


and the factors affecting the attainment of adsorptiondesorption and reaction equilibria.

The formation and adsorption of nongaseous products, e.g., $\mathrm{CH}_{3} \mathrm{OH}$ and $\mathrm{CH}_{2} \mathrm{O}$, also need to be considered when trying to establish a mass balance. The FTIR spectrum of the $10 \% \mathrm{TiO}_{2} / \mathrm{Ru}$ catalyst following reaction shows alkyl, carbonyl, and $\mathrm{C}-\mathrm{O}$ vibrations (Figure 7).

The most reactive catalyst within the series was $10 \% \mathrm{TiO}_{2} / \mathrm{Ru}$, converting approximately $1.2 \mu \mathrm{mol}$ of $\mathrm{CO}_{2} \mathrm{~g}$ 1 of catalysth ${ }^{-1}$ (with an apparent quantum efficiency (AQE) of $\sim 0.07 \%$ ), compared to conversions of 0.4 and $0.43 \mu \mathrm{mol} \mathrm{g}^{-1} \mathrm{~h}^{-1}$ over the $100 \% \mathrm{Ru}$ and $10 \% \mathrm{Ru} / \mathrm{TiO}_{2}$ catalysts, respectively (Figure 6(c)).

This photocatalyst is robust, maintaining a product evolution rate of $1.2 \mu \mathrm{mol}$ of product $\mathrm{g}^{-1} \mathrm{~h}^{-1}$ for three reaction cycles (Figure 8(a)). Moreover, the pXRD pattern (Figure 8(b)) and the XPS spectra (Figure $8(\mathrm{c})$ ) of the $10 \% \mathrm{TiO}_{2} / \mathrm{Ru}$ catalyst also remained unchanged after three reaction cycles, confirming the stability of this photocatalyst.

The photocatalytic activity of metallic Ru nanoparticles is surprising and may be ascribed to a number of factors. Firstly, as reported by Kim et al., upon chemisorption onto the surface of $\mathrm{Ru}$ nanoparticles, $\mathrm{CO}_{2}$ molecules experience a pronounced narrowing in the energy gap between their HOMO ( $5 \sigma$ bonding) and LUMO ( $2 \pi$ antibonding) levels. They report a decrease from $8.5 \mathrm{eV}$ (free $\mathrm{CO}_{2}$ ) to $2.4 \mathrm{eV}$ ( $\mathrm{Ru}$-bound $\mathrm{CO}_{2}$ species) [25]. The new energy gap of $\mathrm{Ru}-$ $\mathrm{CO}_{2}$ molecules falls within the visible region; hence, adsorbed $\mathrm{CO}_{2}$ molecules can absorb the incident irradiation and this can promote the dissociation reaction.

Secondly, the effect of localised surface plasmon resonance (LSPR) must be considered. It is widely known that "free electrons" on the surface of noble metals can absorb light in the visible range to trigger a collective oscillatory wave (plasmon) which gives rise to creation of hot electrons, electron transfer, and catalytic activity [26]. Also, as reported by Christopher et al., the photocatalysis observed is likely due to polarisation of the $\mathrm{Ru}$ nanoparticles' surface into electron/hole-rich regions, ultimately generating "metallic electrons and holes" [24].

Furthermore, the photocatalysis over pure Ru nanoparticles may be partially attributed to thermal promotion, since light absorption in the range of the LSPR band will lead to a slight temperature rise within the nanoparticles [27]. The combination of thermal and photoenergies to initiate catalytic processes of $\mathrm{CO}_{2}$ conversion is deemed beneficial firstly by Thampi et al. [13] and recently by Kim et al. [25]. In their case, heat was purposefully used alongside light to carry out the hydrogenation of $\mathrm{CO}_{2}$ over $\mathrm{Ru}$ nanoparticles, yielding better overall catalytic performance when both heat and light were used. Therefore, we conclude that the generation of hot electrons from the metallic nanoparticles, the reduced gap between the HOMO and LUMO levels in the adsorbed $\mathrm{CO}_{2}$ molecules, and the photoinduced thermal energy all work in tandem to promote the $\mathrm{CO}_{2}$ photoreduction $[23-25,28]$.

To our knowledge, this is the first example of Ru nanoparticles catalysing the AP reaction. Furthermore, the absorbance of light by the Ru particle generates plasmons (and

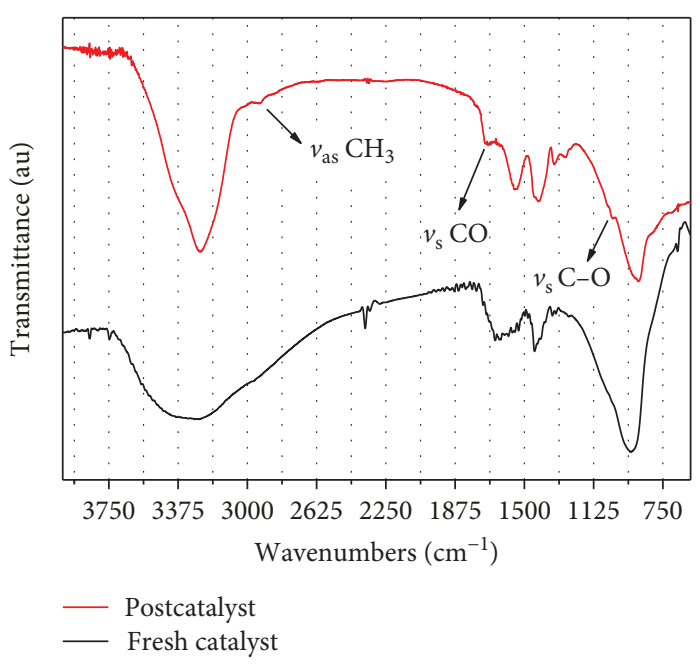

FIGURE 7: FTIR spectrum of the $10 \% \mathrm{TiO}_{2} / \mathrm{Ru}$ catalyst following the AP reaction shown in Figure 6.

these plasmons yield the photocatalytic activity). This is the first example of such plasmonic reactivity seen with $\mathrm{Ru}$ catalysts.

Also, this result shows that anatase $\mathrm{TiO}_{2}$ has a role in the photocatalytic process. Coupling Ru nanoparticles to anatase $\mathrm{TiO}_{2}$ led to higher photocatalytic activity in the case of $10 \% \mathrm{TiO}_{2} / \mathrm{Ru}$, possibly owing to the combined effect of LSPR on $\mathrm{Ru}$ nanoparticles and charge separation at the semiconductor [26]. However, such improvements were not observed over the $10 \% \mathrm{Ru} / \mathrm{TiO}_{2}$ catalyst (suggesting that there is an optimum loading of Ti for this promotion). Moreover, the activity improvement cannot be assigned to enhanced absorption of visible light as all catalysts' absorption of visible light (Figure 5) is comparable.

The addition of $\mathrm{TiO}_{2}$ changes the reaction selectivity (increasing the proportion of $\mathrm{CO}$ in the product mixture) indicating that $\mathrm{TiO}_{2}$ plays a role in the catalysis. However, it must be noted that $\mathrm{TiO}_{2}$ itself cannot be photoexcited under these conditions. Given this, the reaction on $\mathrm{TiO}_{2}$ must involve the transfer of excitons generated on $\mathrm{Ru}$ to $\mathrm{TiO}_{2}$ before they are used in the reaction. Plasmon-induced photocatalysis in $\mathrm{TiO}_{2}$ has previously only been seen in $\mathrm{Au} / \mathrm{TiO}_{2}$ systems [26].

\section{Conclusions}

We have shown the preparation of ruthenium metal nanoparticles using a facile one-pot solvothermal method without the use of templates or of structure-directing agents. The materials formed are nanoparticles with a narrow size distribution and relatively high surface areas and are capable of adsorbing and desorbing $\mathrm{CO}_{2}$ and $\mathrm{H}_{2} \mathrm{O}$. The Ru particles absorb visible light and are active in the promotion of the $\mathrm{CO}_{2}+\mathrm{H}_{2} \mathrm{O}$ reaction under this light via a plasmonic excited state. Incorporation of $\mathrm{Ti}$-containing precursors into the preparation mixture (forming anatase $\mathrm{TiO}_{2}$ in the final materials) changes the light absorption properties, the photocatalytic activity, and $\mathrm{CH}_{4} / \mathrm{CO}$ selectivity of the 


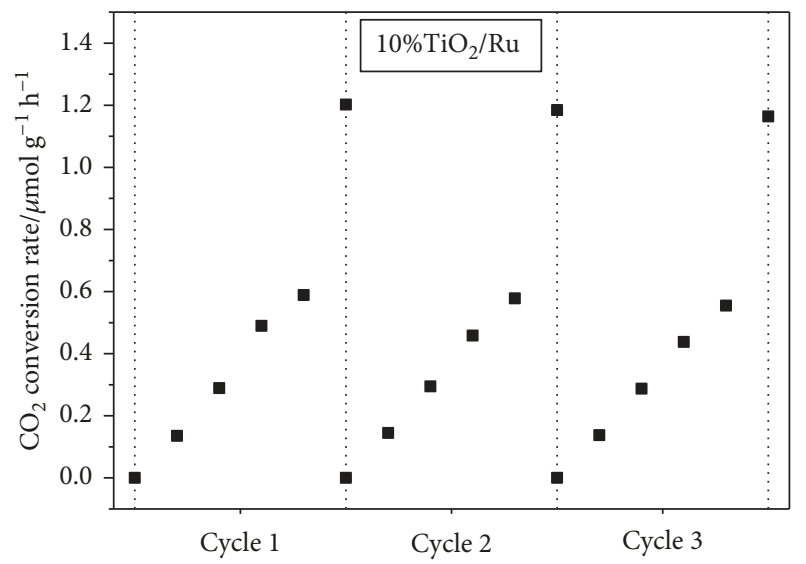

(a)

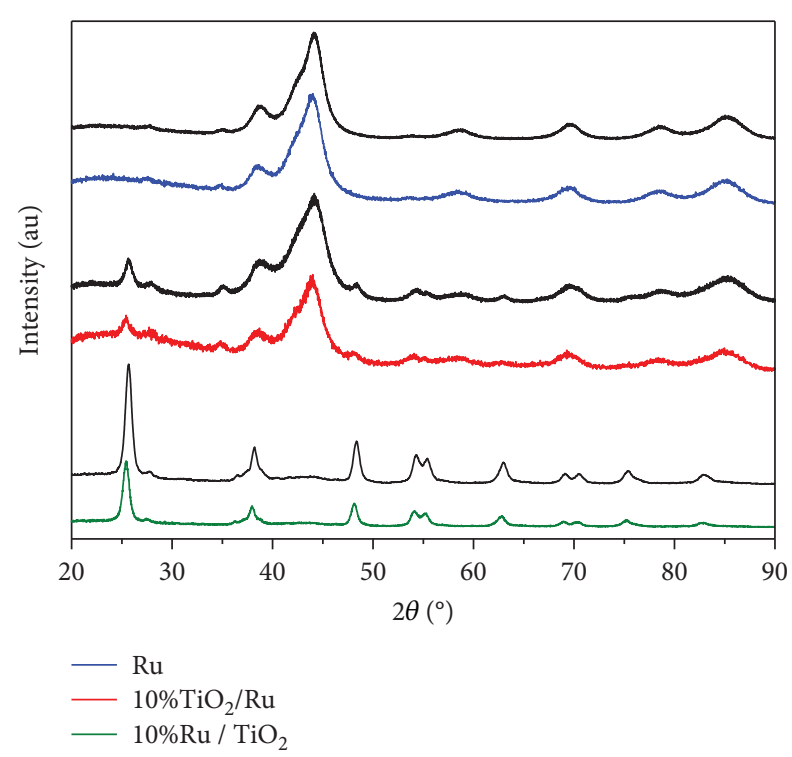

(b)

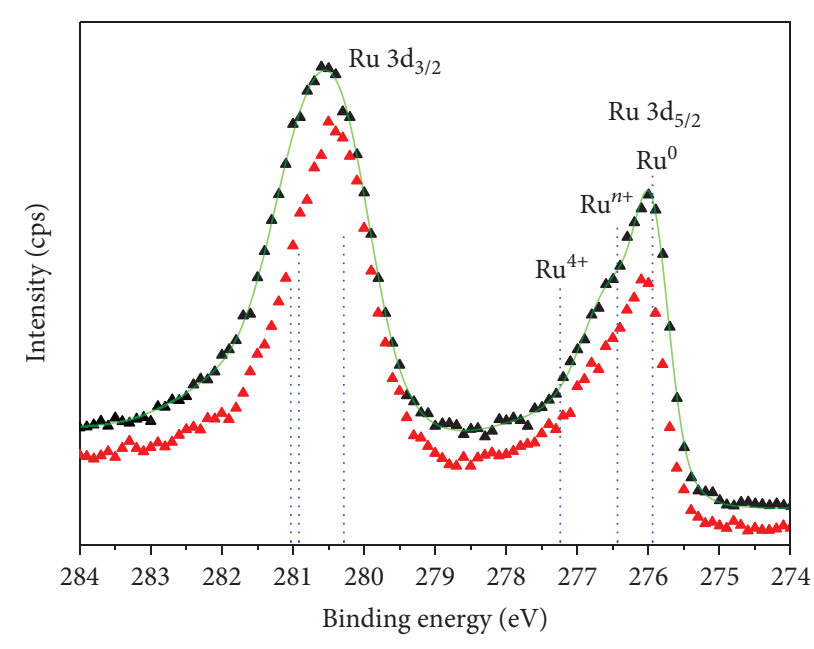

A Fresh catalyst

- Post catalyst

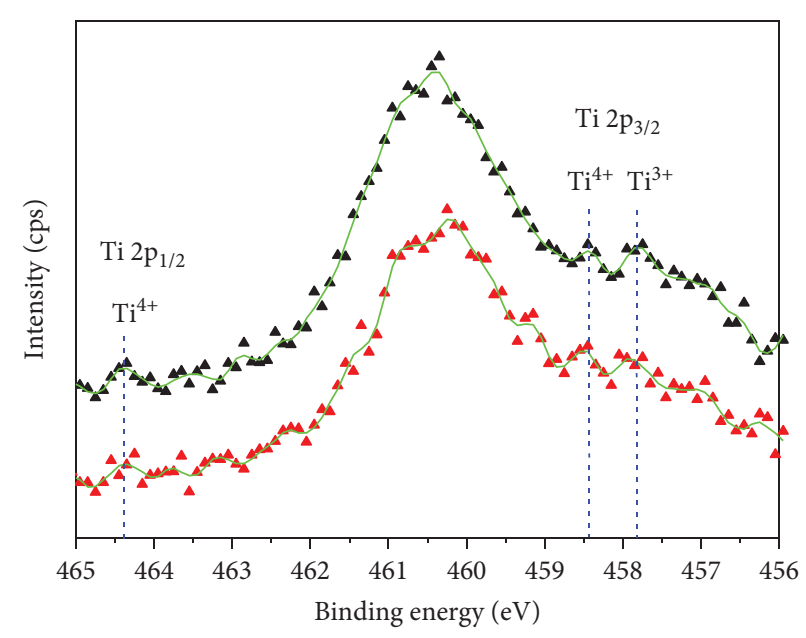

A Fresh catalyst

A Post catalyst

(c)

FIgURe 8: (a) Reactivity of the $10 \% \mathrm{TiO}_{2} / \mathrm{Ru}$ catalyst over three reaction cycles, (b) pXRD profiles for the three catalysts following reaction (compared to the profiles from the fresh catalysts), and (c) XPS profiles of the $10 \% \mathrm{TiO}_{2} / \mathrm{Ru}$ catalyst before and following reaction showing that no surface chemical changes had taken place.

catalysts. The effects of $\mathrm{TiO}_{2}$ appear to be derived from the transfer of plasmon-induced excitons in the $\mathrm{Ru}$ to the $\mathrm{TiO}_{2}$ material.

\section{Data Availability}

The data used to support the findings of this study are available from the corresponding authors upon request.

\section{Conflicts of Interest}

The authors declare that there is no conflict of interest regarding the publication of this paper.

\section{Acknowledgments}

EM is funded by Coordenação de Aperfeiçoamento de Pessoal de Nível Superior (CAPES) through the "Science without Borders (SwB) scheme" supported by the Ministry of Education, Brazil. The publication cost of this paper is provided jointly by the University College Dublin (UCD) Output-Based Research Support Scheme (OBRSS) and UCD College of Engineering \& Architecture internal fund.

\section{Supplementary Materials}

Figure SI 1: UV-visible emission spectrum of the Xe lamp radiation (recorded inside the solar simulator). Figure SI 2: $(\mathrm{a}, \mathrm{b}, \mathrm{c})$ SEM images of $100 \% \mathrm{Ru}, 10 \% \mathrm{TiO}_{2} / \mathrm{Ru}$, and 
$10 \% \mathrm{Ru} / \mathrm{TiO}_{2}$, respectively. Figure SI 3: (a, b, c) Multipoint BET plots for the $100 \% \mathrm{Ru}, 10 \% \mathrm{TiO}_{2} / \mathrm{Ru}$, and $10 \% \mathrm{Ru} / \mathrm{TiO}_{2}$ catalysts, respectively. Figure SI 4: High-resolution XPS Ru $3 \mathrm{~d}$ core-level spectra of the $100 \% \mathrm{Ru}$ and $10 \% \mathrm{TiO}_{2} / \mathrm{Ru}$ materials. (Supplementary Materials)

\section{References}

[1] K. Li, B. Peng, and T. Peng, "Recent advances in heterogeneous photocatalytic $\mathrm{CO}_{2}$ conversion to solar fuels," ACS Catalysis, vol. 6, no. 11, pp. 7485-7527, 2016.

[2] E. T. Kho, T. H. Tan, E. Lovell, R. J. Wong, J. Scott, and R. Amal, "A review on photo-thermal catalytic conversion of carbon dioxide," Green Energy \& Environment, vol. 2, no. 3, pp. 204-217, 2017.

[3] E. Alper and O. Yuksel Orhan, " $\mathrm{CO}_{2}$ utilization: developments in conversion processes," Petroleum, vol. 3, no. 1, pp. 109-126, 2017.

[4] W. Tu, Y. Zhou, and Z. Zou, "Photocatalytic conversion of $\mathrm{CO}_{2}$ into renewable hydrocarbon fuels: state-of-the-art accomplishment, challenges, and prospects," Advanced Materials, vol. 26, no. 27, pp. 4607-4626, 2014.

[5] D. R. Lide, Handbook of Chemistry and Physics, J. R. Rumble, Ed., vol. 71CRC, 99th edition, 2018.

[6] S. N. Habisreutinger, L. Schmidt-Mende, and J. K. Stolarczyk, "Photocatalytic reduction of $\mathrm{CO}_{2}$ on $\mathrm{TiO}_{2}$ and other semiconductors," Angewandte Chemie International Edition, vol. 52, no. 29, pp. 7372-7408, 2013.

[7] E. Albarrán-Zavala and F. Angulo-Brown, "A simple thermodynamic analysis of photosynthesis," Entropy, vol. 9, no. 4, pp. 152-168, 2007.

[8] W. Fan, Q. Zhang, and Y. Wang, "Semiconductor-based nanocomposites for photocatalytic $\mathrm{H} 2$ production and $\mathrm{CO} 2$ conversion," Physical Chemistry Chemical Physics, vol. 15, no. 8, p. 2632, 2013.

[9] A. Dhakshinamoorthy, S. Navalon, A. Corma, and H. Garcia, "Photocatalytic $\mathrm{CO}_{2}$ reduction by $\mathrm{TiO}_{2}$ and related titanium containing solids," Energy \& Environmental Science, vol. 5, no. 11, pp. 9217-9233, 2012.

[10] C. Yang, Y. Yu, B. LindenVan Der, and J. C. S. Wu, "Artificial Photosynthesis over Crystalline TiO2-Based Catalysts: Fact or Fiction?," Journal of the American Chemical Society, vol. 74, no. 13, pp. 8398-8406, 2010.

[11] Y. Xia, Y. Xiong, B. Lim, and S. E. Skrabalak, "Shape-controlled synthesis of metal nanocrystals: simple chemistry meets complex physics?," Angewandte Chemie International Edition, vol. 48, no. 1, pp. 60-103, 2009.

[12] T. Naota, H. Takaya, and S.-I. Murahashi, "Rutheniumcatalyzed reactions for organic synthesis," Chemical Reviews, vol. 98, no. 7, pp. 2599-2660, 1998.

[13] K. R. Thampi, J. Kiwi, and M. Grätzel, "Methanation and photo-methanation of carbon dioxide at room temperature and atmospheric pressure," Nature, vol. 327, no. 6122, pp. 506-508, 1987.

[14] H. W. King, "Quantitative size-factors for metallic solid solutions," Materials Science, vol. 1, no. 1, pp. 79-90, 1966.

[15] A. R. Denton and N. W. Ashcroft, "Vegards law," Physics Review A, vol. 43, no. 6, pp. 3161-3164, 1991.

[16] N. J. Halas, S. Lal, W. S. Chang, S. Link, and P. Nordlander, "Plasmons in strongly coupled metallic nanostructures," Chemical Reviews, vol. 111, no. 6, pp. 3913-3961, 2011.
[17] D. D. E. Jr and G. Chumanov, "Synthesis and Optical Properties of Silver Nanoparticles and Arrays," ChemPhysChem, vol. 29634, no. 6, pp. 1221-1231, 2005.

[18] J. Mao, L. Ye, K. Li et al., "Pt-loading reverses the photocatalytic activity order of anatase $\mathrm{TiO}_{2}\left\{\begin{array}{lll}0 & 0 & 1\end{array}\right\}$ and $\left\{\begin{array}{lll}0 & 1 & 0\end{array}\right\}$ facets for photoreduction of $\mathrm{CO}_{2}$ to $\mathrm{CH}_{4}$," Applied Catalysis B: Environmental, vol. 144, pp. 855-862, 2014.

[19] C. D. Wagner, W. M. Riggs, L. E. Davis, and J. F. Moulder, Handbook of X-Ray Photoelectron Spectroscopy, Perkin-Elmer Corporation, 1978.

[20] K. S. Kim and N. Winograd, "X-Ray photoelectron spectroscopic studies of ruthenium-oxygen surfaces," Journal of Catalysis, vol. 35, no. 1, pp. 66-72, 1974.

[21] T.-D. Nguyen-Phan, S. Luo, D. Vovchok et al., “Three-dimensional ruthenium-doped $\mathrm{TiO}_{2}$ sea urchins for enhanced visible-light-responsive $\mathrm{H}_{2}$ production," Physical Chemistry Chemical Physics, vol. 18, no. 23, pp. 15972-15979, 2016.

[22] M. Zayats, A. B. Kharitonov, S. P. Pogorelova, O. Lioubashevski, E. Katz, and I. Willner, "Probing photoelectrochemical processes in au-cds nanoparticle arrays by surface plasmon resonance: application for the detection of acetylcholine esterase inhibitors," Journal of the American Chemical Society, vol. 125, no. 51, pp. 16006-16014, 2003.

[23] S. Sun, W. Wang, L. Zhang, M. Shang, and L. Wang, “Ag@C core/shell nanocomposite as a highly efficient plasmonic photocatalyst," Catalysis Communications, vol. 11, no. 4, pp. 290-293, 2009.

[24] P. Christopher, H. Xin, and S. Linic, "Visible-light-enhanced catalytic oxidation reactions on plasmonic silver nanostructures," Nature Chemistry, vol. 3, no. 6, pp. 467-472, 2011.

[25] C. Kim, S. Hyeon, J. Lee et al., "Energy-efficient CO2 hydrogenation with fast response using photoexcitation of $\mathrm{CO} 2$ adsorbed on metal catalysts," Nature Communications, vol. 9, no. 1, pp. 1-8, 2018.

[26] A. Furube, L. Du, K. Hara, R. Katoh, and M. Tachiya, "Ultrafast plasmon-induced electron transfer from gold nanodots into $\mathrm{TiO}_{2}$ nanoparticles," Journal of the American Chemical Society, vol. 129, no. 48, pp. 14852-14853, 2007.

[27] X. Zhang, Y. L. Chen, R. S. Liu, and D. P. Tsai, "Plasmonic photocatalysis," Reports on Progress in Physics, vol. 76, no. 4, pp. 46401-46441, 2013.

[28] L. Collado, A. Reynal, J. M. Coronado, D. P. Serrano, J. R. Durrant, and V. A. de la Peña O'Shea, "Effect of Au surface plasmon nanoparticles on the selective $\mathrm{CO}_{2}$ photoreduction to $\mathrm{CH}_{4}$," Applied Catalysis B: Environmental, vol. 178, pp. 177-185, 2015. 

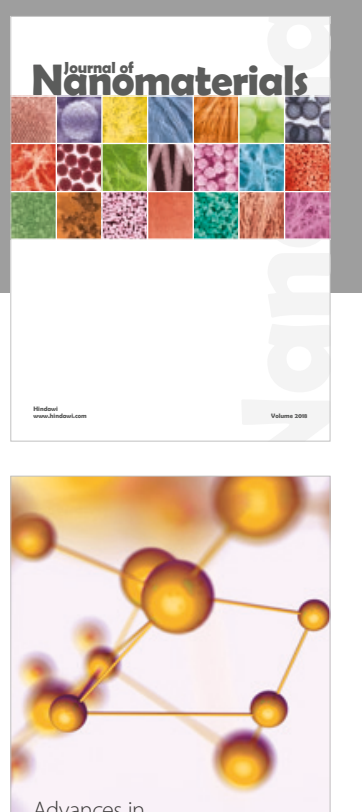

Physical Chemistry
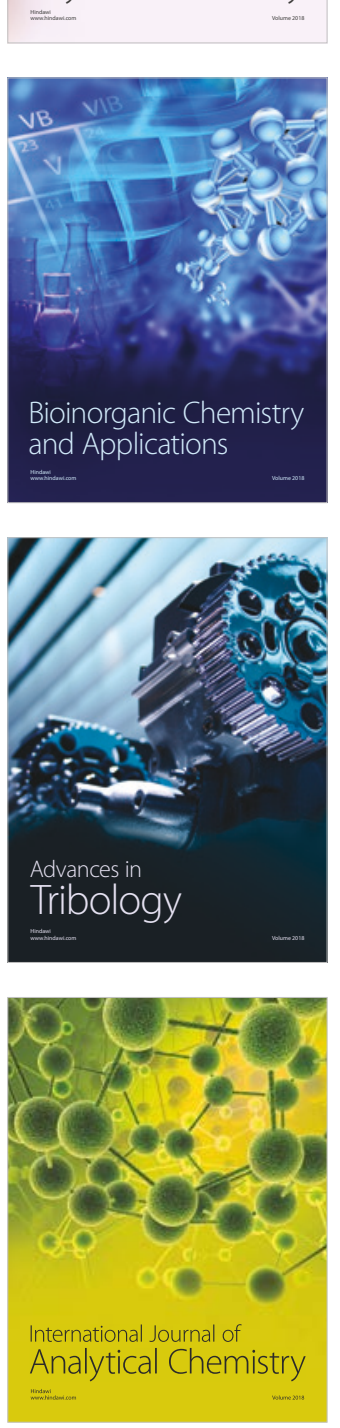

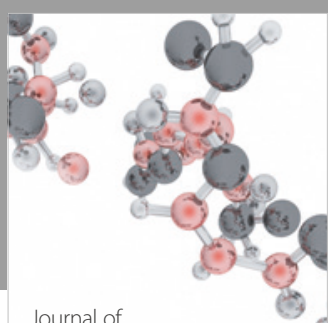

Analytical Methods

in Chemistry

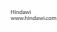

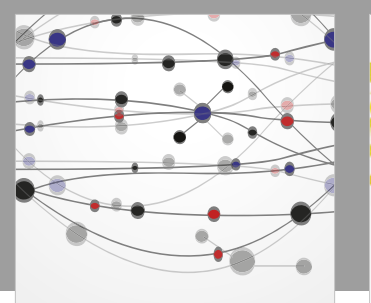

The Scientific World Journal

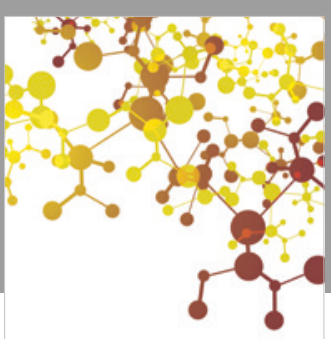

Journal of

Applied Chemistry
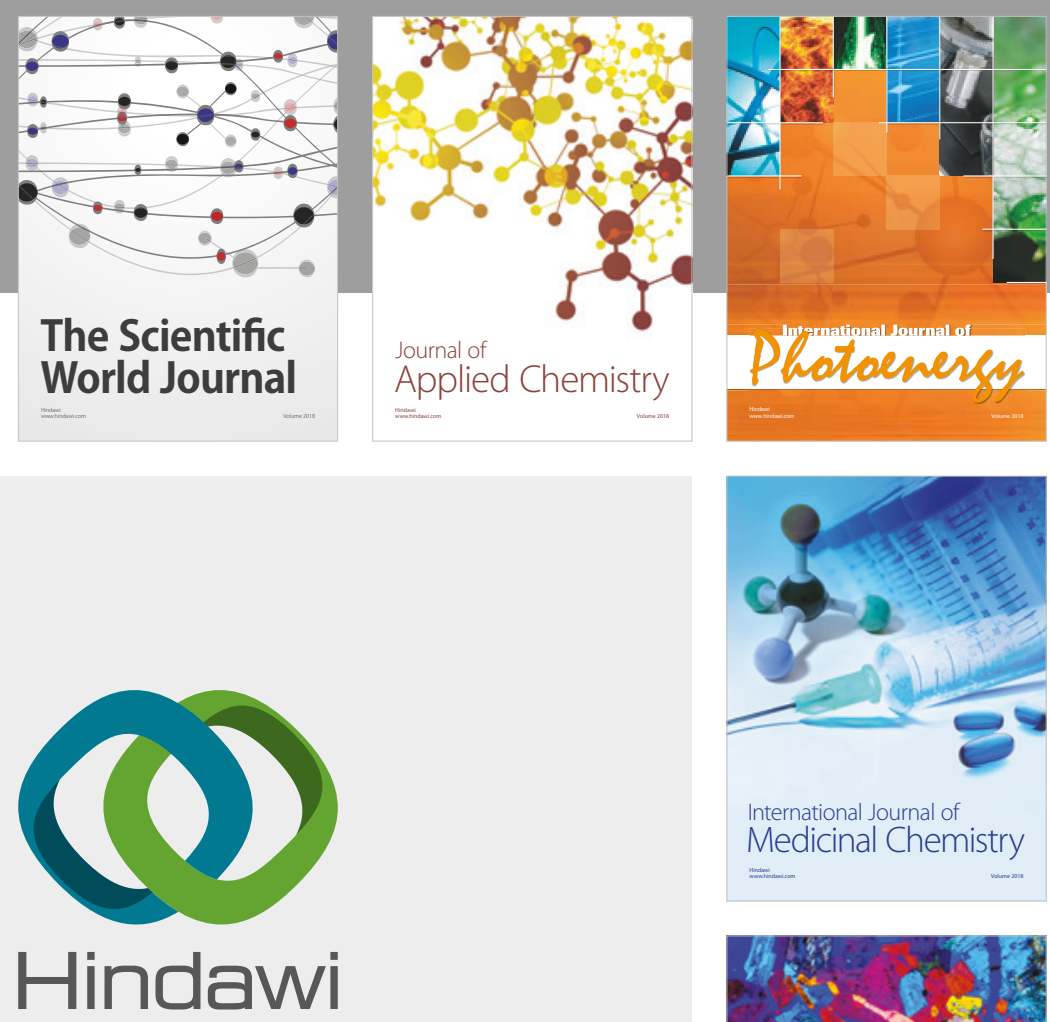

Submit your manuscripts at

www.hindawi.com
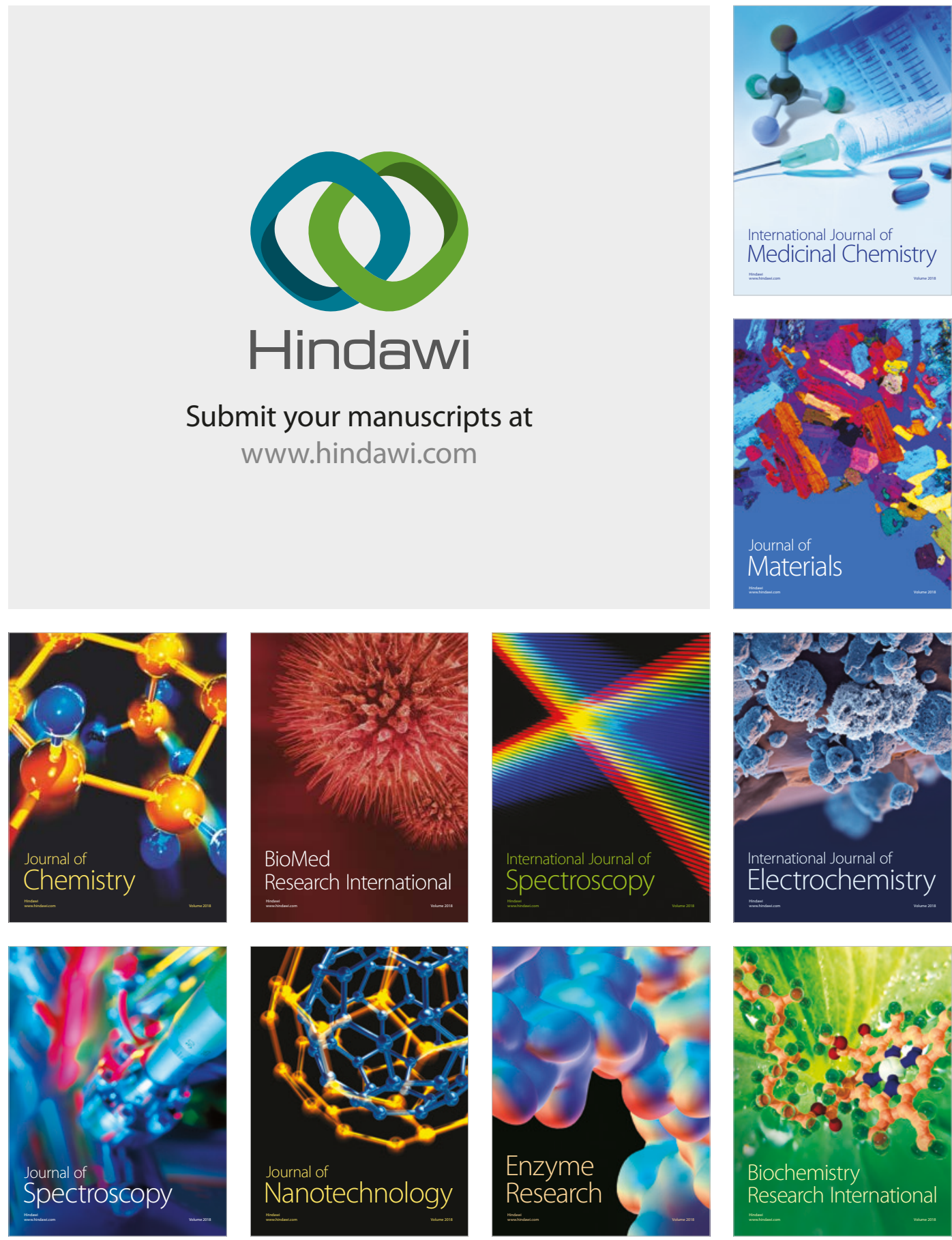
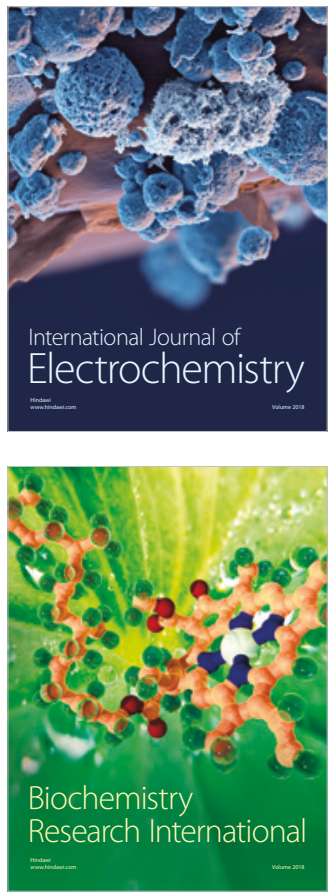